\title{
ANALISA PRESTRESS METODE POST TENSION PADA BALOK PROYEK SUPERMALL PAKUWON INDAH PHASE-3 SURABAYA
}

\author{
Yohana Pricilia ${ }^{1)}$, Koespiadi ${ }^{2}$ \\ ${ }^{1)}$ Prodi Teknik Sipil, Universitas Narotama,pricilia8893@gmail.com \\ ${ }^{2)}$ Prodi Teknik Sipil, Universitas Narotama, koespiadi@narotama.ac.id
}

\begin{abstract}
ABSTRAK
Proyek Supermall Pakuwon Indah Phase-3 Surabaya adalah proyek yang terdiri dari 2 tower dan 1 mall, pada atap mallnya akan dibangun area kolam renang, dengan bentangan yang cukup panjang maka pekerjaan balok menggunakan metode prestress post tension. Balok yang dianalisa adalah tipe PC-G810. Balok tersebut di analisa menggunakan SNI 7833-2012 dan SNI 2847-2013. Desain beton menggunakan fc'35 MPa fy $500 \mathrm{MPa}$ untuk tulangan baja. Diameter strand 12,7 mm dengan tegangan tarik batas 1.900 $\mathrm{MPa}$ dan Modulus elastisitas $197.000 \mathrm{MPa}$. Perhitungan gaya-gaya dalam dihitung menggunakan Autodesk Robot Structural Analysis Professional 2012. Dan Autocad 2012 digunakan untuk gambar teknis. Hasil analisa balok PC-G810 ini menurut SNI kurang memenuhi persyaratan untuk ditinjau dari aspek kehilangan akibat gaya prategang.
\end{abstract}

Kata kunci : analisa, prategang, post-tension

\section{PENDAHULUAN}

Proyek Supermall Pakuwon Indah Phase-3 Surabaya ini adalah proyek lanjutan dari Proyek Supermall Pakuwon Indah Phase-2 yang terletak pada Surabaya Barat, yang dimiliki oleh PT. Pakuwon Grup. Direncanakan pada roof mallnya akan dibangun swimming pool yang akan menunjang fasilitas pada bangunan ini. Dikarenakan area yang cukup luas sehingga menyebabkan bentang balok pada proyek ini sangatlah panjang. Guna mendapatkan hasil konstruksi yang efektif, efisien, dan ekonomis maka dipilihlah metode pelaksanaannya menggunakan beton prategang dengan metode posttension. Pelaksanaan di lapangan dilakukan oleh PT. Pembangunan Perumahan (Persero, Tbk) selaku Kontraktor Utama pada proyek SPI Phase-3, sedangkan perhitungan dan analisa dilakukan oleh PT. VSL Indonesia selaku Sub-Kontraktor. Namun hasil analisa tersebut perlu dianalisa kembali kebenarannya sebagai bahan pembelajaran.

\section{KAJIAN PUSTAKA}

Stuktur beton prategang atau pratekan didefinisikan sebagai suatu sistem struktur beton khusus dengan cara memberikan tegangan awal tertentu pada komponen sebelum digunakan untuk mendukung beban luar sesuai dengan yang diinginkan. (Istimawan, 
1993:377).Penarikan purna (post-tensioning) didefinisikan sebagai cara memberikan prategangan pada beton, di mana tendon baru ditarik setelah betonnya dicetak terlebih dahulu dan mempunyai cukup kekerasan untuk menahan tegangan sesuai dengan yang diinginkan. Pelaksanaan cara ini pada dasarnya terdiri dari enam langkah : (Istimawan, 1993:382).

\section{METODOLOGI}

1. Pengumpulan data

Data-data yang diperlukan dalam perencanaan adalah:
a. Gambar kerja proyek
b. Data kabel prategang
c. Peraturan-peraturan yang digunakan
d. Analisa SNI

2. Perhitungan Balok Prestress

3. Perhitungan pembebanan

Perhitungan beban-beban yang bekerja disesuaikan dengan peraturan pembebanan.

Analisa pembebanan adalah sebagai berikut:
a. Beban mati
Terdiri dari beban sendiri balok, spesi, keramik, beban wall.
b. Beban hidup
Ditentukan PPIUG 1983

4. Analisa gaya dalam

Untuk analisa gaya dalam dilakukan secara manual kemudian untuk perhitungan momen dan reaksi perletakan yang terjadi menggunakan program analisa struktur

Komponen-komponen struktur didesain sesuai dengan aturan yang terdapat pada SNI 2847-2013. Perhitungan meliputi:
a. Kontrol penulangan
b. Sketsa gambar penulangan
c. Perhitungan kehilangan gaya prategang
d. Perhitungan kuat lentur, dll 


\section{PEMBAHASAN}

Berikut akan dibahas penulangan Balok G48 Lantai 1 Adapun data-data perhitungan penulangan adalah sebagai berikut:

Data-data Perencanaan

a. Dimensi

Panjang balok : $16,73 \quad \mathrm{~m}$

Lebar $\quad: 800 \quad \mathrm{~mm}$

Tinggi $\quad: 1.000 \quad \mathrm{~mm}$

b. Strand

Spesifikasi strand yang digunakan pada balok PC-G810 adalah sebagai berikut :

Material : Sevenwire Stress-relieve uncoated strand

Type dan Grade : Nominal diameter $12,7 \mathrm{~mm}$

Nominal steel area $0,987 \mathrm{~cm} 2$

Minimum ultimate tension strength $183,7 \mathrm{kN}$

Min yield tension strength $156,1 \mathrm{kN}$

Spesifikasi : ASTM A416-90 (Grade 270)- Low Relaxation

c. Data Beton :

Bentang balok : 16,73 $\mathrm{m}$

Kuat tekan awal (fc'i): $35 \quad \mathrm{MPa}$

Kuat tekan akhir (fc's): 40,50 MPa

Lebar balok : $0,8 \quad \mathrm{~m}$

Tinggi balok $: 1,00 \quad \mathrm{~m}$

d. Data Baja Prategang :

Dimensi strand 1/2" : 12,7 $\mathrm{mm}$

Luas penampang efektif: $0,987 \quad \mathrm{~cm} 2$

Tegangan tarik batas: $1.900 \quad \mathrm{MPa}$

Modulus elastisitas $\quad: 197.000 \quad \mathrm{MPa}$

Nilai asumsi draw-in: $6 \quad \mathrm{~mm}$

Waktu perawatan : $28 \quad$ hari

e. Data Tendon :

Faktor distribusi beban hidup : $100 \%$

Presentase penarikan tendon : $75 \%$

Diameter tendon $\quad: 100 \mathrm{~mm}$

Jumlah maksimum tiap tendon: 15 buah

Analisis Penampang

$\mathrm{St}>1,20(\mathrm{Ms}-\mathrm{Mi}) /(\mathrm{ft}, \mathrm{i}-\mathrm{fc}, \mathrm{S}) ; \mathrm{Sb}>1,20(\mathrm{Ms}-\mathrm{Mi}) /(\mathrm{ft}, \mathrm{S}-\mathrm{fc}, \mathrm{i})$

$\mathrm{Mi}:$ Momen akibat beban balok $: 1 / 8$ (q balok) (L2)

Ms : Momen akibat beban total $: 1 / 8$ (q balok) (L2)

Mi : 67.230,52 $\mathrm{kg} / \mathrm{m}$

Ms $: 185.438,43 \quad \mathrm{~kg} / \mathrm{m}$ 
St $\quad>62.161 .579,43 \quad \mathrm{~mm} 3$

$\mathrm{Sb}>73.084 .168,23 \quad \mathrm{~mm} 3$

$\mathrm{St}=$ Statis momen $=1 / 6 \cdot \mathrm{b} \cdot \mathrm{h} 2$

Didapatkan nilai $\mathrm{h}=1.142,64 \mathrm{~mm}$; dan nilai $\mathrm{b}=761,76 \mathrm{~mm}$.

$\mathrm{Sb}=$ Statis momen $=1 / 6 . \mathrm{b} . \mathrm{h} 2$

Didapatkan nilai $\mathrm{h}=1.205,99 \mathrm{~mm}$; dan nilai $\mathrm{b}=804,00 \mathrm{~mm}$.

Nilai $\max \mathrm{h}=1.205,99 \mathrm{~mm}$; dibulatkan menjadi $1.200 \mathrm{~mm}$.

Nilai max $b=603,00 \mathrm{~mm}$; dibulatkan menjadi $600 \mathrm{~mm}$.

Maka perencanaan awal balok 800 x $1.000 \mathrm{~mm}$ kurang memenuhi persyaratan, diasumsikan besarnya $\mathrm{b}=1 / 2 \mathrm{~h}$.

Kehilangan Gaya Prategang

1. Perpendekan Elastis Beton

2. $\mathrm{ES}=\Delta \mathrm{fc}=(\mathrm{n} . \mathrm{Pi}) / \mathrm{Ac} ; \mathrm{ES}=\quad 6.02 \times 187.5 \dot{3}^{\circ 0}$

$$
\mathrm{ES}=1,41 \mathrm{MPa} \sim 0,07 \%
$$

$(\mathrm{P} 1-\mathrm{P} 2) / \mathrm{P} 1=-\mathrm{K} \mathrm{L}-\mu \alpha$

Dimana : L : $17,78 \mathrm{~m} ; \alpha: 0,15 ; \mu: 0,2 ; \mathrm{K}: 0,01$

- K L $-\mu \alpha=-(0,01.17,78)-(0,2$. 0,15) $=-0,21=20,86 \%$

3. Akibat Slip di Pengangkuran

Besarnya perpanjangan total tendon :

$\Delta \mathrm{L}=\mathrm{fc} / \mathrm{Es} \mathrm{L} ; \Delta \mathrm{L}=1.900 / 197.000 \quad 16.737 ; \Delta \mathrm{L}=161,42 \mathrm{~mm}$

Kehilangan gaya prategang akibat slip :

$\mathrm{ANC}=(\mathrm{S}$ rata-rata $) / \Delta \mathrm{L} \times 100 \%$

$\mathrm{ANC}=2,5 / 161,42 \times 100 \% ; \mathrm{ANC}=1,55 \%$

4. Akibat Creep (Rangkak)

$\mathrm{CR}=\varphi . \mathrm{fc} . \mathrm{Es} / \mathrm{Ec}$

$\mathrm{CR}=1,2$. 16 . 197.000/32.700 ; $\mathrm{CR}=115,76 \mathrm{MPa}$

Jadi prosentase kehilangan tegangan pada baja prategang :

$\% \mathrm{CR}=\mathrm{CR} / \mathrm{fi} 100 \% ; \% \mathrm{CR}=115,76 / 1.900100 \% ; \% \mathrm{CR}=6,09 \%$

5. Akibat Penyusutan Beton

$\mathrm{SH}=\varepsilon \mathrm{cr}$. Es

$\mathrm{SH}=0,00014$. $197.000 ; \mathrm{SH}=26,67 \mathrm{MPa}$

$\mathrm{fsi}=75 \% \mathrm{x} \mathrm{fpu}=75 \% \times 1.900=1.425 \mathrm{Mpa}$

Prosentase kehilangan gaya prategang :

$\% \mathrm{SH}=(\mathrm{SH} / \mathrm{fsi}) \times 100 \%=1,87 \%$

6. Akibat Relaksasi Baja Prategang

$\mathrm{RE}=\mathrm{R}(1-(2 \times \mathrm{ECS}) / \mathrm{Fpi})$

$\mathrm{RE}=2,5(1-(2 \times 142,43) / 1.900) ; \mathrm{E}=0,0213 \mathrm{MPa}=2,13 \%$

Tabel 1. Perhitungan Stressing Pada Balok

\begin{tabular}{|c|c|c|}
\hline Presentase Penarikan & $\begin{array}{c}\text { Tegangan Pada } \\
\text { Manometer }(\mathrm{MPa})\end{array}$ & Pemuluran (mm) \\
\hline $25 \%$ & 10,72 & 235 \\
\hline $50 \%$ & 21,43 & 265 \\
\hline $70 \%$ & 32,15 & 303 \\
\hline $100 \%$ & 42,86 & 235 \\
\hline
\end{tabular}

Pemuluran yang diterima 
$=(303-265)+(265-235)+(235-200) ;=38+30+35=103 \mathrm{~mm}$

Pemuluran kotor : $(103 \times 4) / 3=137,33 \mathrm{~mm}$

Penyesuaian pemuluran : 137,33-4-6+2=93,33 $\mathrm{mm}$

Perbedaan pemuluran $=$ penyesuaian pemuluran - pemuluran ideal

$=93,33-123,30=-29,967 \mathrm{~mm}$

Presentase pemuluran $=($ perbedaan pemuluran $) /($ pemuluran ideal $) \times 100 \%$

$=(-29,967) / 123,300 \times 100 \%=-0,24 \%$

Berdasarkan perhitungan diatas didapat nilai deviasi sebesar $-0,24 \%$. Karena nilai deviasi berdasarkan perhitungan berada diantara $-7 \%$ dan $7 \%$, maka balok PCG810 sudah memenuhi persyaratan dalam balok prategang.

Desain Terhadap Lentur

Tegangan yang Diijinkan Pada Tendon Prategang.

Sesuai SNI tegangan tarik pada tendon tidak boleh melebihi :

Penentuan nilai fpy untuk post-tension adalah 0,90 . fpu

Akibat gaya penarikan (jacking) :

Tegangan tarik pada tendon tidak boleh melebihi 0,94 fpy

$=0,94 \times 1.710=1.607,4 \mathrm{MPa}$

dan harus lebih kecil dari 0,80 fpu dan nilai maksimum yang direkomendasikan oleh produsen tendon $;=0,80 \times 1.900=1.520 \mathrm{MPa}$

Segera setelah transfer gaya prategang :

Tegangan tarik pada beton tidak boleh melebihi 0,82 fyp

$=0,82 \times 1.710=1.402,2 \mathrm{MPa}$

dan tidak boleh lebih besar dari : $0,74 \mathrm{fpu} ;=0,74 \times 1.900=1.406 \mathrm{MPa}$

Pada beton prategang dengan sistem pasca tarik, pada daerah angkur dan sambungan segera setelah penyaluran gaya prategang. Tegangan tarik pada tendon tidak boleh melebihi $0,70 \mathrm{fpu}$.

$=0,7 \times 1.900=1.330 \mathrm{MPa}$

Dimana : fpy : $1.710 \mathrm{MPa}$; fpu $: 1.900 \mathrm{Mpa}$

Daerah Batas Penempatan Tendon

Batas titik inti (kern) terbawah :

$\mathrm{Kb}=\square 1 / 12 \mathrm{~h} \square{ }^{\wedge} 2 /(1 / 2 \mathrm{~h})=1 / 6 \mathrm{~h}=1 / 6 \times 1.000=166,67 \mathrm{~mm}$

Dengan cara yang sama dapat dihitung pula batas titik inti (kern) teratas :

$\mathrm{Ka}=\mathrm{r}^{\wedge} 2 / \mathrm{Y} \_\mathrm{b}=1 / 6 \mathrm{~h}=1 / 6 \times 1.000=166,67 \mathrm{~mm}$

Demikian pula untuk arah mendatar dapat diketahui batas titik inti dari titik berat penampang : $1 / 6 \mathrm{~b}=1 / 6 \times 800=133,33 \mathrm{~mm}$.

\section{Daerah Batas Eksentrisitas Disepanjang Bentang Balok}

Jika MD adalah momen akibat beban mati (Mmin), maka lengan kopel antara garis pusat tekanan (C-line) dan garis pusat tendon (cgs) adalah amin.

$\mathrm{MD}=\mathrm{Mmin}=\mathrm{Pi} \times \operatorname{amin} ; \operatorname{amin}=\mathrm{M} \_\mathrm{D} / \mathrm{Pi}=0,356 \mathrm{~m}$

Nilai ini menunjukkan jarak maksimum dibawah batas bawah (terendah) daerah kern (inti).

Jika MT adalah momen total akibat beban mati, beban mati tambahan dan beban hidup (Mmaks), maka lengan kopel antara garis pusat tekanan (C-line) dan garis pusat tendon (cgs) adalah amaks.

$\mathrm{MT}=$ Mmaks $=$ Pc $\mathrm{x}$ amaks $;$ Amaks $=\mathrm{M} \_\mathrm{T} / \mathrm{Pe}=0,481 \mathrm{~m}$

Perencanaan Untuk Kekuatan Lentur Dan Daktilitasi 
Karena penulangan non prategang tidak diperhitungkan, maka :

$\omega=0$ dan juga $\omega^{\prime}=0$

$\mathrm{fps}=1.900(1-0,90 / 0,81(0,0075 \times 1.900 / 35+0))=1.044,45 \mathrm{MPa}$

$\omega \mathrm{p}=\rho \mathrm{p} . \mathrm{fps} / \mathrm{fc}^{\prime}=0,0075.1 .044,45 / 35=0,223$

Untuk komponen struktur dengan tulangan prategang, tulangan tarik dan tulangan tekan non prategang :

$\omega \mathrm{p}+\left(\omega-\omega^{\prime}\right) \mathrm{d} / \mathrm{dp} \leq 0,36 \beta 1$

$0,223+0 \leq 0,36 \times 0,81$

$0,223 \leq 0,292$ ..OK

Proses Desain Penampang

Kabel prategang terdiri dari $15 \varnothing 12,7$ x2

Kabel prategang terletak $854 \mathrm{~mm}$ dari sisi atas balok prategang

$\mathrm{fps}=1.900(1-0,4 / 0,81(0,0075 \times 1.900 / 35+0))=1.519,75 \mathrm{MPa}$

$\mathrm{Tp}=\mathrm{fps}$. Aps $=1.519,75 \times 3.798,38=5.772 .600 \mathrm{~N}=5.772 \mathrm{kN}$

Regangan pada baja prategang $\varepsilon p$ :

$\varepsilon \mathrm{p}: \mathrm{fps} / \mathrm{Ep}=1.519,75 / 197.000=0,0077$

$\mathrm{c}: \varepsilon \mathrm{u}^{\prime}=(\mathrm{dp}-\mathrm{c}): \varepsilon \mathrm{p} ; \mathrm{c}: 0,003=(854-\mathrm{c}): 0,0077$

$0,0077 \mathrm{c}=0,003(854-\mathrm{c}) ; \mathrm{c}=239,11$

$\mathrm{a}=\beta 1 \mathrm{c}=0,81 \times 239,11=193,68 \mathrm{~mm}$

Momen nominal yang dapat dipikul oleh penampang :

$\mathrm{Mn}=\mathrm{Tp}(\mathrm{dp}-1 / 2 \mathrm{a})=5.772(854-1 / 2 \times 193,68)=4.370 .771,4 \mathrm{kNmm}$

$\mathrm{Mn}=4.370 \mathrm{kNm}$

Jadi momen maksimum yang dapat dipikul oleh penampang : $\mathrm{Mu}=\varnothing \mathrm{Mn}$

Faktor reduksi kekuatan untuk lentur $\varnothing=0,8$

$\mathrm{Mu}=0,8 \times 4.370=3.496,62 \mathrm{kNm}$

Perhitungan Pembesian Non Prategang

Beton : :11,08 m3

Formwork Side : 27,70 m2

Formwork Soffit : $12,59 \mathrm{~m} 2$

Sehingga didapatkan rasio besi sebesar, 160,39 kg/m3

Panjang kabel prestress : 35,56 m

\section{KESIMPULAN}

Tabel 2 Rincian Perencanaan

\begin{tabular}{|l|l|l|}
\hline & \multicolumn{1}{|c|}{ Balok PC-G810 (fersi RLB) } & \multicolumn{1}{|c|}{ Standart SNI Prategang } \\
\hline DimensiBalok & $800 \times 1.000 \mathrm{~mm}$ & $600 \times 1.200 \mathrm{~mm}$ \\
\hline \multirow{3}{*}{ Strand } & Sevenwire stress-relieve uncoated & Sevenwire stress-relieve uncoated strand \\
& strand. & Nominal diameter $9,53 \mathrm{~mm}$ \\
& Nominal diameter $12,7 \mathrm{~mm}$ & Nominal steel area $54,84 \mathrm{~mm}^{2}$ \\
& Nominal steel area $98,71 \mathrm{~mm}^{2}$ & $($ T.Y Lin dkk -2000$)$ \\
\hline Duct & $\varnothing 84(13<$ jumlah strand dalam & $\varnothing 84(13<$ jumlah strand dalam duct $\leq 19)$ \\
\hline
\end{tabular}




\section{NAROTAMA JURNAL TEKNIK SIPIL \\ e-ISSN: $2460-3430$}

VOLUME 3 NOMOR 1 JUNI 2019

\begin{tabular}{|c|c|c|}
\hline & duct $\leq 19$ ) & (T.Y Lin dkk - 2000) \\
\hline Angkur & $\begin{array}{l}\text { Angkurhidup 19S danangkurmati } \\
19 \mathrm{H}\end{array}$ & $\begin{array}{l}\text { Angkurhidup 19S danangkurmati 19U } \\
\text { (tergantungjumlah strand) } \\
\text { (T.Y Lin dkk - 2000) }\end{array}$ \\
\hline Grouting & $\begin{array}{l}\text { 1. Semen tipe I } 50 \mathrm{~kg} \text { ( } 1 \text { zak }) \\
\text { 2. Air }(40-45 \% \text { berat semen }) \\
\text { 3. Cebex-100 }(0,45 \% \text { dariberat } \\
\text { semen })\end{array}$ & $\begin{array}{l}\text { Semen } \\
\text { denganzatadditifseperticebexatausirkagrout }\end{array}$ \\
\hline Beton & $\begin{array}{l}\mathrm{Fc}^{\prime}=35 \mathrm{MPa} \\
\text { (umur } 28 \text { hari) }\end{array}$ & $\begin{array}{l}\mathrm{Fc}^{\prime}=28-55 \mathrm{MPa} \\
\text { (umur } 28 \text { hari) } \\
(\mathrm{T} . Y \text { Lin dkk }-2000 \text { ) }\end{array}$ \\
\hline PresentasePemuluran & $-0,24 \%$ & $-7 \%-7 \%$ \\
\hline $\begin{array}{l}\text { Kehilangan Gaya Prategang: } \\
\text { 1. PerpendekanElastisBeton } \\
\text { 2. AkibatGeseranSepanjang Tendon } \\
\text { 3. Akibat Slip di Pengangkuran } \\
\text { 4. Akibat Creep (Rangkak) } \\
\text { 5. AkibatPenyusutanBeton } \\
\text { 6. AkibatRelaksasi Baja Prategang }\end{array}$ & $\begin{array}{ll}\text { 1. } & - \\
\text { 2. } & - \\
\text { 3. } & \\
\text { 4. } & 5,28 \% \\
\text { 5. } & - \\
\text { 6. } & 2,89 \%\end{array}$ & $\begin{array}{ll}\text { 1. } & 0,07 \% \\
\text { 2. } & 20,86 \% \\
\text { 3. } & \\
\text { 4. } & 6,55 \% \\
\text { 5. } & 1,87 \% \\
\text { 6. } & 2,13 \%\end{array}$ \\
\hline $\begin{array}{lllll}\text { Tegangan } & \text { Tarik di } & \text { serat paling } \\
\text { bawah } & & & & \\
\end{array}$ & $7,07 \mathrm{~N} / \mathrm{mm}^{2}$ & $2,95 \mathrm{~N} / \mathrm{mm}^{2}$ \\
\hline fpy & $1.195 \mathrm{Mpa}$ & $1.710 \mathrm{Mpa}$ \\
\hline $\begin{array}{l}\text { Tegangan yang Diijinkanpada } \\
\text { Tendon } \\
\text { 1. Akibat Gaya Penarikan } \\
\text { 2. SegeraSetelah Transfer Gaya } \\
\text { Prategang } \\
\text { 3. Tegangan Tarik Pada Tendon }\end{array}$ & $\begin{array}{l}\text { Tegangan yang Diijinkanpada } \\
\text { Tendon } \\
\text { 1. } \\
\text { Tidakbolehmelebihi } 1,607,4 \\
\quad \text { Mpa ; haruslebihkecildari } \\
\quad 956,2 \text { Mpa } \\
\text { 2. } \quad \text { Tidakbolehmelebihi } 1.402,2 \\
\quad \text { Mpa ; } \\
\text { tidakbolehlebihbesardari } \\
\quad 884,5 \text { Mpa } \\
\text { 3. } \quad \text { Tidakbolehmelebihi } 836,7 \\
\text { Mpa }\end{array}$ & $\begin{array}{l}\text { Tegangan yang Diijinkanpada Tendon } \\
\text { 1. Tidakbolehmelebihi } 1,607,4 \mathrm{Mpa} \text {; } \\
\text { haruslebihkecildari } 1.520 \mathrm{Mpa} \\
\text { 2. Tidakbolehmelebihi } 1.402,2 \mathrm{Mpa} \text {; } \\
\text { tidakbolehlebihbesardari } 1.406 \mathrm{Mpa} \\
\text { 3. Tidakbolehmelebihi } 1.330 \mathrm{Mpa}\end{array}$ \\
\hline
\end{tabular}




\section{DAFTAR PUSTAKA}

1. Anonim, (2013). SNI 2847. Persyaratan Beton Struktural Untuk Bangunan Gedung. Jakarta: Badan Standarisasi Nasional.

2. Anonim, (2012). SNI 7833. Tata Cara Perancangan Beton Pracetak dan Beton Prategang Untuk Bangunan Gedung. Jakarta: Badan Standarisasi Nasional.

3. Anonim, (2003). SNI 03-1726. Tata Cara Perencanaan Ketahanan Gempa untuk Bangunan Gedung. Jakarta: Badan Standarisasi Nasional.

4. Anonim, (2002). SNI 03-2847.Tata Cara Perhitungan Struktur Beton Untuk Bangunan Gedung (Beta Version). Jakarta: Badan Standarisasi Nasional.

5. Anonim, (1981). Peraturan Pembebanan Indonesia Untuk Gedung 1983. Bandung: Direktorat Penyelidikan Masalah Bangunan.

6. Soetoyo,Ir, (2002). Konstruksi Beton Pratekan. Surabaya Jurusan Teknik Sipil Fakultas Teknik Institut Teknologi Sepuluh November.

7. Dipohusodo,Istimawan, (1993). Struktur Beton Bertulang.

8. Koespiadi. (2016). "Technology Model Precast Foundation For Eco-Friendly Solution”. Proceeding Forum in Research, Science, and Technology (FIRST) 2016 vol.

9. Anonim, Handout Struktur Beton Bertulang dan Pratekan.

10. Anonim, Tugas Beton Prategang.

11. Yulianti, R.C, Beton Prategang. Pusat Pengambangan Bahan Ajar - UMB.

12. Masnul, C.R, (2009). Analisa Prestress(Post-Tension) Pada Precast Concrete U Girder. Bidang Studi Struktur Departemen Teknik Sipil Fakultas Teknik USU. 